\title{
COMMENTARY
}

\section{Hydroxyethylstarch 200/0.5 - the horse has bolted}

Neil Soni*

See related research by Simon et al., http://ccforum.com/content/16/1/R16

\begin{abstract}
Hydroxyethylstarch (HES) 200/0.5 is associated with renal failure. Several studies have suggested that renal function is affected but the subsequent arguments leave the clinician in no man's land. A recent study in Critical Care by Simon and colleagues using a two hit animal model of shock demonstrates that the use of a higher molecular weight starch, HES $200 / 0.5$, is associated with impaired renal function when compared with ringers acetate, gelatin or a lower molecular weight starch, HES 130/0.42. The authors conclude that both the lower molecular weight starch and the ringers acetate 'preserve renal function and attenuate tubular damage better than $10 \%$ hydroxyethylstarch 200/0.5 in saline.' Added to the previous evidence, the renal effects of HES200/0.5 are probably real. Many clinicians have already moved to the lower molecular weight starches on the basis of doubt rather than certainty, but this study tips the balance. The cause remains elusive and the lack of a mechanism should be seen as a problem.
\end{abstract}

\section{Introduction}

The paradox that using higher molecular weight starches to prevent organ failure might actually cause it has been an anxiety. The authors of a recent paper in Critical Care are to be congratulated for trying to nail the issue of whether hydroxyethylstarch (HES) 200/0.5 is associated with renal failure [1]. Colloids such as Dextran 40 have been similarly implicated but the culprit, this time, is allegedly the hyperoncotic higher molecular weight HES 200/0.5 [2]. In 1993 the possibility of renal effects was raised [3]. The evidence included the presence of the same osmotic nephrosis lesions that were seen with Dextran 40 and functional changes. These renal lesions are found with various colloids, not just HES, and their

*Correspondence: n.soni@imperial.ac.uk

Department of Anaesthetics and Intensive Care, Chelsea and Westminster Hospital, London SW10 9NH, UK relevance to renal impairment is loose association rather than cause. They are lysozomes and it is suggested that while they might be a marker of early injury, they are not usually involved with functional effects and usually resolve without sequelae [4]. Perhaps not such a refined end point. Not so with either interstitial cell proliferation, which was not measured in the study by Simon and colleagues [1], nor necrosis, which was [5]. Both HES and gelatins had 'increased' acute tubular necrosis (ATN) but only HES 200/0.5 rates mention. As both haemorrhagic and septic shock can cause ATN, response to shock in animals is variable and actual histological ATN in humans is probably low, it would be wise to be cautious in attributing these histological changes to the fluid.

The functional changes were first described when HES 220/0.6 given to renal donors was associated with impaired renal function in the subsequent recipients, although this was contentious [6,7]. In septic shock, HES 200/0.5 was also associated with apparent renal impairment but these are complex populations despite the simple collective title and so any findings are in the context of both relatively small and heterogenous populations and are considered by some to be inconclusive $[8,9]$.

There was a real and cogent reason to use a controlled laboratory study to provide a calibrated insult, control the circumstances and to define specific endpoints, which is what Simon and colleagues [1] have done.

The double hit insult was haemorrhagic shock followed by septic shock. The former seemed to cause only relatively minor effects, without even much tachycardia, but the impressive changes occurred in the second part of the study during the septic phase. The raging tachycardia in all groups except the sham group confirms that there has been a major insult with evidence of sympathetic compensation. The variability in timing and impact of either haemorrhage or sepsis or both in individual mammals precludes any conclusion about which or both is the bigger insult. It is the endpoints that are interesting.

The change in renal function is unequivocal. Creatinine clearance, and the N-acetyl-beta-D-glucosaminidase (NAG)/creatine ratio, accompanied by a lower, albeit not significant, urine output, all indicate detriment in the HES 200/0.5 group. And constitutes evidence. The important secondary finding is that ringers acetate, 
gelatin and HES 130/0.42 seem relatively similar to each other with regard to affect on renal function.

Cause and effect remains unresolved. Interpret the inflammatory markers as you wish, but, at best, it is association and not cause and effect. The intensive care preoccupation about chloride shows it was higher and the $\mathrm{pH}$ lower in the animals given HES 200/0.6, which is based in saline, although the values are remarkably unremarkable. Acetate was common to several solutions, is historically considered a cause of haemodynamic instability during haemodialysis and hence enjoyed a poor reputation in renal medicine but was not implicated here. Its reputation has, incidentally, been resuscitated by its use in resuscitation [10]. The oncotic effect of colloids has both history and epidemiological association as a potential mechanism [11]. In this study the demonstrated values seem relatively small [1].

The crux of the matter is the lack of a mechanism and the study by Simon and colleagues cannot answer that question. No mechanism means no real closure, and uncertainty will remain as to whether other molecules in this class, whether starches or colloids in general, might have similar effects. Rather than wait for studies to show epidemiological association, a basic science approach should have a role. For a speciality it is not enough to know there is a problem: it is important to know why.

Clinical pragmatism is important. We should accept that HES200/0.5 has a detrimental effect on renal function. Whether HES $130 / 0.4$ and Ringers acetate 'preserve' function or HES 200/0.5 impairs function is a moot but important point. Surely the latter. Many intensivists have moved to lower molecular weight starches already and, pragmatically, as these smaller starches are easily available why persist with the larger ones?

\section{Conclusion}

Accept that there is a risk of renal impairment with HES 200. A positive note in this study is that HES $130 / 0.42$ does not pose a similar risk but also compares favourably with the other solutions available. The vital question remains why. Unless we understand the mechanism we will remain dependent on serendipitous epidemiological findings to identify iatrogenicity, as is highlighted by these adverse effects that, after a decade, are still probable rather than definite. This is inappropriate for fluids that are fundamental to the supportive medicine we practice. We use them like lolly water, yet our knowledge base appears pitifully poor. The mechanism will not be found on epidemiological fishing trips and we must move from bedside to bench. The paper by Simon and colleagues confirms the presence of a problem, demonstrates the usefulness of a controlled study, highlights the ignorance around the mechanism and demands research to find the mechanism. Fluids are not the only area where epidemiological findings seem to trump the need to know the mechanism. This study may be closing the stable door after the horse has bolted but there are other doors and other horses where this approach may be sensible.

\section{Abbreviations}

ATN, acute tubular necrosis; HES, hydroxyethylstarch.

Competing interests

NS has lectured and acted as an independent advisor for Fresenius Kabi Ltd.

Published: 16 February 2012

References

1. Simon T-P, Schuerholz T, Huter L, Sasse M, Heyder F, Pfister W, Marx G: Impairment of renal function using hyperoncotic colloids in a two hit model of shock: a prospective randomized study. Crit Care 2012, 16:R16.

2. Biesenbach G, Kaiser W, Zazgornik J: Incidence of acute oligoanuric renal failure in dextran 40 treated patients with acute ischemic stroke stage III or IV. Ren Fail 1997, 19:69-75.

3. Legendre C, Thervet E, Page B, Percheron A, Noel LH, Kreis H: Hydroxyethylstarch and osmotic-nephrosis-like lesions in kidney transplantation. Lancet 1993, 342:248-249.

4. Dickenmann M, Oettl T, Mihatsch MJ: Osmotic nephrosis: acute kidney injury with accumulation of proximal tubular lysosomes due to administration of exogenous solutes. Am J Kidney Dis 2008, 51:491-503.

5. Huter L, Simon TP, Weinmann L, Schuerholz T, Reinhart K, Wolf G, Amann KU, Marx G: Hydroxyethylstarch impairs renal function and induces interstitial proliferation, macrophage infiltration and tubular damage in an isolated renal perfusion model. Crit Care 2009, 13:R23

6. Cittanova ML, Leblanc I, Legendre C, Mouquet C, Riou B, Coriat P: Effect of hydroxyethylstarch in brain-dead kidney donors on renal function in kidney-transplant recipients. Lancet 1996, 348:1620-1622.

7. Coronel B, Mercatello A, Martin X, Lefrancois N: Hydroxyethylstarch and renal function in kidney transplant recipients. Lancet 1997, 349:884; author reply 884 .

8. Schortgen F, Lacherade JC, Bruneel F, Cattaneo I, Hemery F, Lemaire F, Brochard L: Effects of hydroxyethylstarch and gelatin on renal function in severe sepsis: a multicentre randomised study. Lancet 2001, 357:911-916.

9. Brunkhorst FM, Engel C, Bloos F, Meier-Hellmann A, Ragaller M, Weiler N, Moerer O, Gruendling M, Oppert M, Grond S, Olthoff D, Jaschinski U, John S, Rossaint R, Welte T, Schaefer M, Kern P, Kuhnt E, Kiehntopf M, Hartog C, Natanson C, Loeffler M, Reinhart K; German Competence Network Sepsis (SepNet): Intensive insulin therapy and pentastarch resuscitation in severe sepsis. N Engl J Med 2008, 358:125-139.

10. McCague A, Dermendjieva M, Hutchinson R, Wong DT, Dao N: Sodium acetate infusion in critically ill trauma patients for hyperchloremic acidosis. Scand J Trauma Resusc Emerg Med 2011, 19:24.

11. Moran M, Kapsner C: Acute renal failure associated with elevated plasma oncotic pressure. N Engl J Med 1987, 317:150-153.

doi:10.1186/cc11155

Cite this article as: Soni N: Hydroxyethylstarch 200/0.5 - the horse has bolted. Critical Care 2012, 16:110 